Volume 2, Nomor 1, Tahun 2020 Hal 339 - 351

\title{
Peningkatan Pemahaman Masyarakat tentang Teknis Perbaikan dan Pelebaran Jembatan Penyeberangan Sungai Kecil di Kelurahan Cawang
}

\author{
L.E. Hutabarat ${ }^{1}$, Simanjuntak, $P^{2}$., Mulyani, A.S ${ }^{3}$, Simanjuntak, R.M. \\ 1,2,3Universitas Kristen Indonesia, Jakarta, Indonesia \\ E-mail: Lolom.Hutabarat@uki.ac.id; pstak03@yahoo.com; agnesyani 79@yahoo.com; \\ rismasimanjuntak@gmail.com;
}

\begin{abstract}
Abstrak
Kawasan hunian di Kelurahan Cawang membutuhkan penataan agar lebih baik dan dapat mendekati pola standar hunian yang layak. Penataan lingkungan kawasan seperti ini perlu dilaksanakan secara berkelanjutan karena seiring dengan berjalannya waktu kawasan perkotaan akan mengalami keterbatasan ruang kota, permukiman yang padat, sistem sanitasi yang buruk serta minimnya ruang publik masyarakat. Salah satu sarana yang dapat diandalkan dalam pergerakan masyarakat di kelurahan ini diantaranya jembatan penyebrangan yang sering dilalui warga untuk keperluan sehari-hari. Peningkatkan pemahaman masyarakat tentang penataan lingkungan di kawasan Kelurahan Cawang dilaksanakan melalui kegiatan PKM Prodi Teknik Sipil FT UKI berupa pendampingan teknis untuk pelebaran jembatan selama total 120 jam yang dimulai dari survei, perencanaan, konsultasi dan asistensi, finalisasi gambar teknis, penyusunan tata kerja, serta persiapan pelaksanaan termasuk pelatihan tenaga kerja. Hasil pendampingan ini telah meningkatkan kesadaran masyarakat dalam memahami konsep dan pengertian kondisi lingkungan secara fisik yang aman, sehat dan nyaman.
\end{abstract}

Kata Kunci: penataan lingkungan, pendampingan teknis, pelebaran jembatan Cawang

\begin{abstract}
Residential areas in Cawang Village need better structuring and can approach a standard pattern of adequate housing. Regional environmental management like this needs to be implemented in a sustainable manner because over time the urban area will experience limited urban space, dense settlements, poor sanitation systems and lack of public public space. One reliable means of community movement in this kelurahan is the crossing bridge that is often used by residents for daily needs. Enhancing the community's understanding of environmental management in the Cawang area is carried out through the PKM Civil Engineering Study Program PKM activities in the form of technical assistance for bridge widening for a total of 120 hours starting from surveys, planning, consultation and assistance, finalizing technical drawings, preparing work procedures, and preparing implementation includes workforce training. The results of this assistance have increased public awareness in understanding the concepts and understanding of physical conditions that are safe, healthy and comfortable.
\end{abstract}

Keywords:. Regional environmntal management, technical assistance, bridge widening

\section{PENDAHULUAN}

\author{
Meningkatnya
}

pertumbuhan

penduduk di Kota Jakarta menimbulkan

adanya konsekuensi pada masalah

lingkungan yang membutuhkan

pembinaan dan penataan menuju lingkungan yang lebih baik,ramah dan manusiawi. Beberapa kawasan di daerah perkotaan seringkali secara fisik tidak layak menjadi kawasan untuk hunian yang memenuhi standar yang secara umum dinamakan dengan kampung kota. Kampung kota adalah 
Volume 2, Nomor 1, Tahun 2020 Hal 339 - 351

suatu bentuk permukiman di wilayah perkotaan yang khas Indonesia dimana penduduknya masih memiliki ikatan kekeluargaan yang erat sebagaimana kehidupan perdesaan dengan kerapatan bangunan dan kerapatan penduduk tinggi. Disamping itu kondisi fisik bangunan dan lingkungan tidak beraturan dan kurang baik serta kurangnya sarana pelayanan dasar seperti air bersih, saluran air limbah dan air hujan, pembuangan sampah dan lainnya (Makhmud, D. F. dkk, 2017).

Kawasan hunian di Kelurahan Cawang merupakan salah satu kampung kota yang berada di Kecamatan Kramat Jati. Berdasarkan data Biro Pusat Statistik luas kawasan ini adalah 1,75 km² (BPS, 2017) yang mencakup $13,46 \%$ dari wilayah Kecamatan Kramat Jati. Jumlah penduduk berdasarkan data tahun 2016 sebanyak 13.041 kepala keluarga dengan total penduduk 39.602 yang terbagi atas $12 \mathrm{RW}$ dan $121 \mathrm{RT}$ dengan tingkat kenaikan penduduk setiap tahun sebesar $0,46 \%$ dengan kelompok umur terbanyak adalah pada usia 20-50 tahun yang masih merupakan usia produktif. Untuk itulah kawasan hunian ini membutuhkan penataan agar lebih baik dan dapat mendekati pola standar hunian yang layak. Dalam mencapai hal tersebut diperlukan pendampingan pada masyarakat untuk membantu kesadaran mereka agar dapat secara mandiri meningkatkan kualitas tata lingkungannya sehingga mampu mendekati pola tata lingkungan yang aman, sehat dan nyaman.

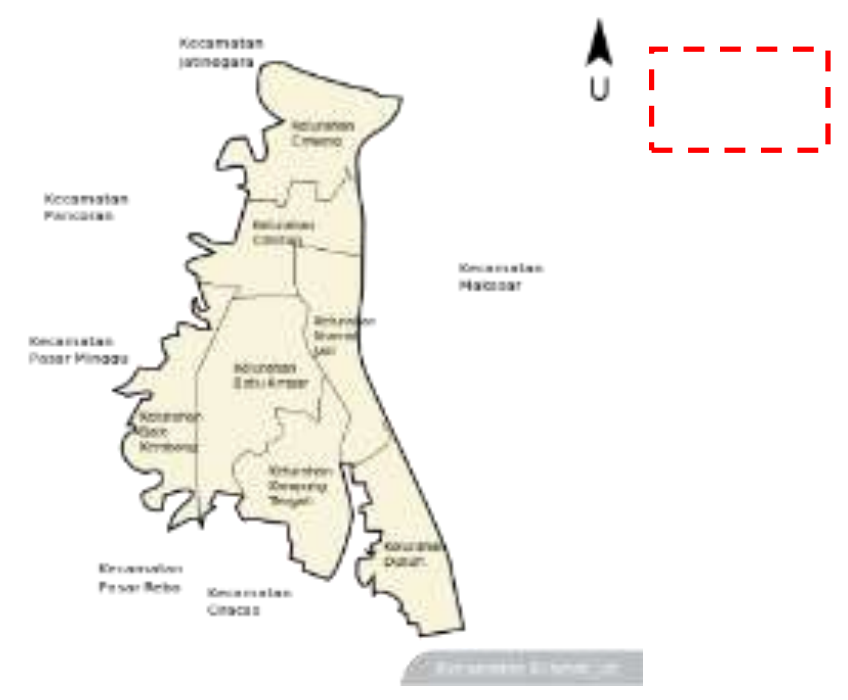

\section{Gambar 1. Lokasi Kelurahan Cawang}

Penataan lingkungan kawasan kelurahan Cawang perlu dilaksanakan secara berkelanjutan karena seiring dengan berjalannya waktu kawasan perkotaan akan mengalami keterbatasan ruang kota, permukiman yang padat, sistem sanitasi yang buruk serta minimnya ruang publik masyarakat. Kawasan ini merupakan mitra stategis kegiatan pengabdian kepada masyarakat oleh Prodi Teknik Sipil FT UKI. Namun untuk menjaga kontiunitas kesadaran 
Volume 2, Nomor 1, Tahun 2020 Hal 339 - 351 masyarakat maka diperlukan strategi pelaksanaan yang tepat. Untuk itu mendampingi masyarakat supaya dapat secara mandiri meningkatkan kualitas kawasannya secara efektif dan berkelanjutan maka pendampingan akan dimulai dari tingkat $\mathrm{RT}, \mathrm{RW}$ dan akhirnya seluruh kawasan Kelurahan Cawang dapat memperoleh manfaat dari Pengabdian masyarakat yang dilakukan oleh Prodi Teknik Sipil.

Analisis karakteristik sarana dan prasarana penunjang di kelurahan Cawang sangat penting untuk mengetahui kondisi, ketersediaan dan kebutuhan sarana dan prasarana penunjang dalam kawasan pemukiman kampung kota. Secara umum ketersediaan dan kebutuhan pada kawasan pemukiman dapat dilihat dari kondisi dan manajemen pelayanannya (Nursyahbani, R. dkk, 2015). Dengan latar belakang kondisi lingkungan dikelurahan Cawang sekarang, pengabdian difokuskan pada penataan lingkungan fisik khususnya penanganan pelebaran jembatan.

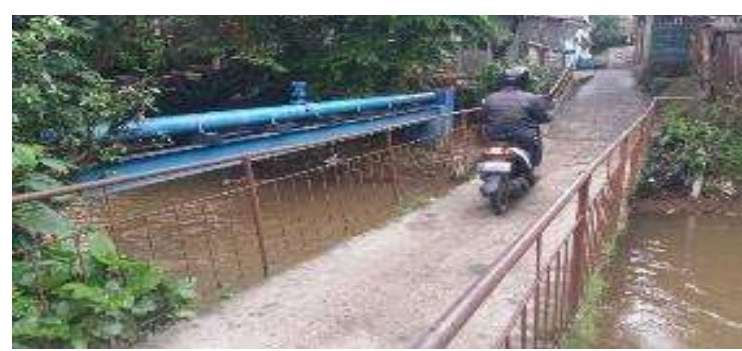

Gambar 1. Kondisi jembatan penyebrangan Cawang eksisting
Salah satu sarana yang dapat diandalkan dalam pergerakan masyarakat di kelurahan ini diantaranya jembatan penyebrangan yang sering dilalui warga untuk keperluan sehari-hari mereka, dengan harapan ini dapat berdampak pada kelancaran arus pergerakan orang dan kendaraan yang melewatinya. Untuk meningkatkan fungsi jembatan tersebut solusinya adalah jembatan ini diperlebar sehingga dapat memberikan keleluasaan pada pergerakan orang dan kendaraan yang melewatinya. Dengan rencana konstruksi pelebaran jembatan penyebrangan tersebut diharapkan dapat membantu tertatanya sarana fisik pada lingkungan tersebut. Proses konstruksi nantinya akan dilaksanakan dengan swadaya masyarakat sehingga diharapkan terbangunnya kesadaran masyarakat untuk membangun, memelihara dan mengembangkan kegiatan penataan lingkungan yang berbasiskan kegiatan pada masyarakat itu sendiri.

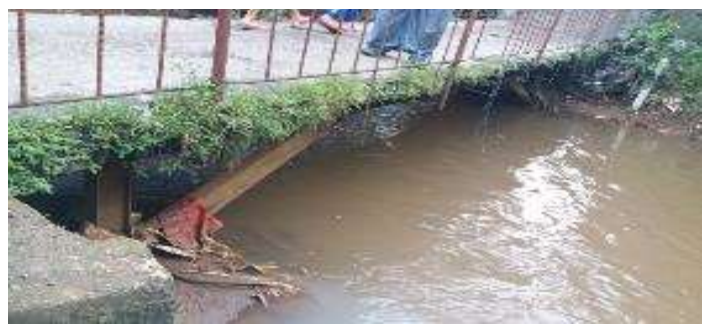

Gambar 2. Bagian bawah jembatan penyebrangan Cawang eksisting 
Volume 2, Nomor 1, Tahun 2020 Hal 339 - 351

\section{METODE}

Berdasarkan hal tersebut diatas maka Prodi sipil FT UKI merencanakan kegiatan Pengabdian Kepada Masyarakat ini dengan tahapan sebagai berikut:

1. Model pendampingan kepada masyarakat adalah sebagai upaya pengembangan program edukasi kepada masyarakat melalui polapola yang lebih berorientasikan pada peningkatan kualitas sumber daya manusia yang memiliki responsibilitas dan tangung jawab yang tinggi terhadap lingkungannya. Keterlibatan secara langsung dan bersama-sama masyarakat menghadapi dan menyelesaikan masalah, merupakan program pengabdian yang sangat efektif. Karena selain memberikan manfaat kepada masyarakat di satu sisi, pola semacam ini juga secara akademis merupakan implementasi nilai-nilai keilmuan dosen untuk mengemban fungsi Tri Dharma perguruan Tinggi.

2. Model Perencanaan dan Perancangan pelebaran Jembatan kali kecil. Perencanaan pelebaran jembatan dilakukan dengan melihat kondisi eksisting awal jembatan asalnya dan dilakukan pelebaran sebatas keperluan yang memungkinkan, hal ini direncanakan dan dibuat gambar teknis secara sederhana yang memenuhi kriteria keamanan struktur serta memenuhi prinsip paling ekonomis dengan tetap mengacu kepada standar yang berlaku di Indonesia (SNI-T-02-2005 dan SNI 03-2833-2008). Pola perencanaan ini juga melibatkan masyarakat pengguna sehingga diharapkan manfaat akan dirasakan oleh masyarakat penggunanya kelak pada komunitas masyarakat kampung kota serta turut membangun bersama sebagai bentuk tanggung jawab kemandirian masyarakat. Dengan demikian, bukanlah hal yang sulit untuk melibatkan masyarakat dalam merencanakan, merancang sampai pada proses pembangunan jembatan sesuai dengan kebutuhan.

3. Model Pendampingan masyarakat dalam mengorganisasikan kegiatan pembangunan di masyarakat kampung kota, kegiatan pembangunan lingkungan yang dilaksanakan merupakan program yang relatif sudah berjalan melalui organisasi RT dan RW maupun lurah setempat. Namun dalam beberapa 
Volume 2, Nomor 1, Tahun 2020 Hal 339 - 351

hal yang menyangkut organisasi masih perlu penataan. Hal ini dimaksudkan agar kegiatankegiatan pembangunan yang dilaksanakan masyarakat dapat terorganisir dengan baik dan berkelanjutan. Artinya, dengan pendampingan profesional, kegiatan masyarakat diharapkan lebih terarah dan dapat memberdayakan potensi masyarakat secara optimal.

4. Model yang dikembangkan merupakan penerapan proses pembangunan yang berbasiskan masyarakat setempat, mulai dari pemberdayaan sumber dana lokal sampai pada sumber daya manusia yang melaksanakan pembangunannya. Penggalian dan penguatan cara-cara tradisional seperti iuran/rembugan dana, kerja bakti (gotong royong) serta rembugan warga untuk memusyawarahkan berbagai kegiatan masih tetap menjadi model yang paling efektif diterapkan. Model ini bukanlah hal yang asing bagi masyarakat di daerah pinggiran (kampung kota), karena kegiatankegiatan pembangunan fisik sudah terbiasa dilakukan secara swadaya dan bersama-sama. Sehingga pelaksanaan model seperti ini tidak akan mendapatkan kendala yang berarti.

5. Model berkelanjutan, dengan tercapainya target program pada suatu kasus studi belum dapat dijadikan sebagai indikator keberhasilan program dalam kerangka yang lebih luas. Begitu banyak persoalan yang dihadapi masyarakat baik sosial kemasyarakatan maupun masalah fisik lingkungan yang belum tersentuh. Pada program jangka panjang yang dirancang oleh tim pengabdian pada masyarakat di Kelurahan Kelurahan Cawang, diterapkan model tindak lanjut yang berkesinambungan.

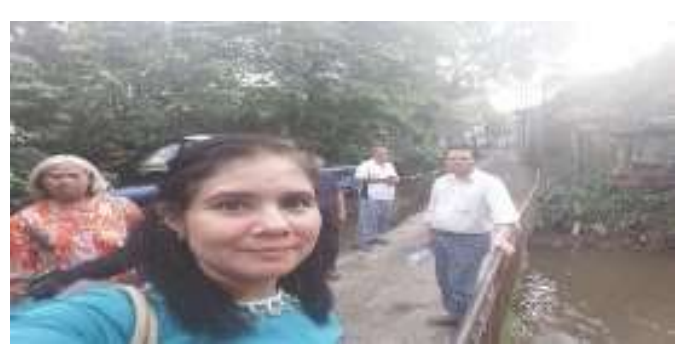

Gambar 3. Survei awal Tim PKM Prodi Sipil kondisi Jembatan Penyebrangan Cawang

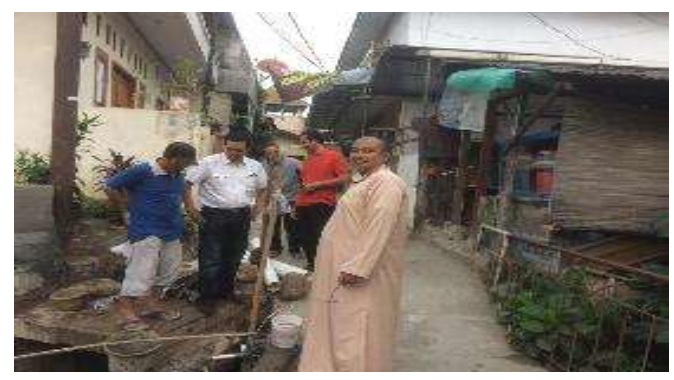

Gambar 4. Asessmen kesiapan warga untuk rencana pelebaran Jembatan Penyebrangan Cawang 
Volume 2, Nomor 1, Tahun 2020 Hal 339 - 351

Adapun lokasi yang dipilih adalah Kawasan Kelurahan Cawang dan dimulai dari kawasan RT 01 RW 10 Jalan Ja'ani Nasir No.7 Kelurahan Cawang Kecamatan Kramat Jati Jakarta Timur rumah. Dasar pemilihan lokasi adalah sebagai salah satu cara meningkatkan keterlibatan serta peran aktif UKI dalam membantu masalah yang dihadapi masyarakat di lingkungan sekitarnya. Program Pengabdian Kepada Masyarakat ini dilakukan oleh dosen dan mahasiswa di Prodi Teknik Sipil Fakultas Teknik UKI untuk merealisasikan keterlibatan perguruan tinggi dalam proses pembangunan yang dilakukan masyarakat baik dalam bentuk pendampingan maupun keterlibatan dalam proses fisik pembangunan.

Kampung kota menjadi titik tolak dalam menemukan urbanitas baru di Asia khususnya di Indonesia yang dapat menjadi kunci dalam membina kehidupan perkotaan yang lebih baik (Nugroho, A. C., 2009). Instrumen perencanaan modern untuk permukiman kota yang menuju pada konsep keberlanjutan terhadap proses yang ada (Lim, W.S.W, 1998) adalah sebagai berikut:

1. Self sufficiency, yaitu pemenuhan kebutuhan kota seoptimal dengan etergantungan pada area sekitar (hinterland) seminimal mungkin, serta bersumber dari proses produksi dan reproduksi dari kota itu sendiri dengan menjaga keseimbangan proporsi alokasi pelayanan dan sumber pembiayaan dalam kota.

2. Land as Resource, optimalisasi penggunaan tanah untuk pembangunan kota sebagai sumber paling vital dengan mengatur penempatan lokasi, kapasitas dan intensitas serta kontrol yang lebih ketat terhadap pembangunan yang akan dilaksanakan. Pengembangan berorientasi pada titik-titik pertumbuhan yang dapat terakses oleh seluruh warga kota dan bukan di pusat kota.

3. Shifting and Floating Values, terkait nilai lahan yang mengambang pada titik-titik pertumbuhan untuk mencegah ekspansi sektor komersial agar tidak merusak tatanan/struktur kota yang ada serta melindungi kawasan-kawasan yang berkarakter dan bersejarah.

4. Transport and Mobility, penyediaan sistem transportasi massal yang layak dan terjangkau yang juga berfungsi untuk mengurangi polusi. Selain itu juga berfungsi untuk 
Volume 2, Nomor 1, Tahun 2020 Hal 339 - 351 mengurangi penggunaan kendaraan pribadi yang dapat menimbulkan degradasi lingkungan kota akibat terlampauinya kapasitas maksimal ruang pergerakan kota.

5. Conservation of Environmental Areas, pelestarian bangunan atau Kawasan bersejarah dari tekanan ekonomi ruang, untuk menjaga identitas dan karakter kota. Upaya yang dilakukan adalah dengan memberikan nilai ekonomi pada bangunan atau kawasan lama (adaptive use), sehingga memiliki legitimasi dan peran yang kuat Sebagai salah satu komponen kota.

Tahapan untuk pelaksanaan kegiatan pendampingan pelebaran jembatan penyebrangan Cawang adalah sebagai berikut:

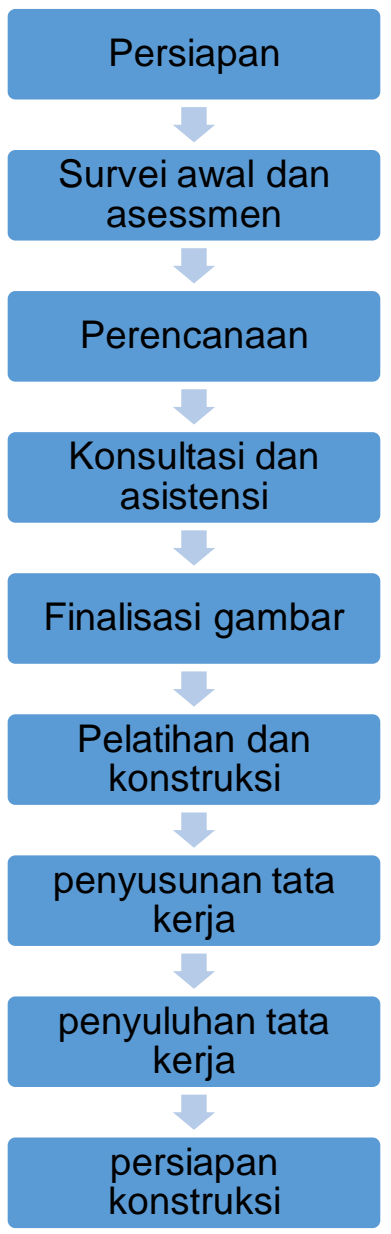

Gambar 5. Skema Pendampingan Teknik Pelebaran Jembatan Penyebrangan Cawang

\section{HASIL DAN PEMBAHASAN}

Berdasarkan

kegiatan

pengabdian tersebut diatas dan berbagai pengalaman sebelumnya maka Prodi sipil FT UKI melaksanakan kegiatan pendampingan pada penataan lingkungan di kawasan Kelurahan Cawang khususnya bimbingan teknis untuk pelebaran jembatan seperti terlihat pada Tabel 1 . 
Volume 2, Nomor 1, Tahun 2020 Hal 339 - 351

Tabel 1. Pendampingan Teknis Pelebaran Jembatan Penyebrangan Cawang

\begin{tabular}{|c|c|c|c|}
\hline Bulan & \multicolumn{2}{|c|}{ Frekuensi pendampingan } & Hasil pendampingan \\
\hline Maret 2018 & Tgl 5, 12, 19 dan 26 & 4 @ 3 jam & survey \\
\hline April 2018 & Tgl 2, 9, 16, 23 dan 30 & 5 @ 3 jam & perencanaan \\
\hline Mei 2018 & Tgl 7, 14, 21 dan 28 & $4 @ 3$ jam & konsultasi dan asistensi \\
\hline Juni 2018 & Tgl 4, 11, 18 dan 25 & $4 @ 3$ jam & Finalisasi gambar \\
\hline Juli 2018 & Tgl 2, 9, 16, 23 dan 30 & 5 @ 3 jam & penyusunan tata kerja \\
\hline Agustus 2018 & $\operatorname{Tg} 6,13,20$ dan 27 & 4 @ 3 jam & penyuluhan tata kerja \\
\hline Septembe r 2018 & Tgl 3, 10, 17 dan 24 & $4 @ 3$ jam & persiapan konstruksi \\
\hline Oktober 2018 & Tgl 1, 8, 15, 22 dan 29 & 5 @ 3 jam & pelatihan dan konstruksi \\
\hline November 2018 & Tgl 5, 12, 19 dan 26 & $4 @ 3$ jam & pelatihan dan konstruksi \\
\hline Desember 2018 & Tgl 3, 10, 17, 24 dan 31 & 5 @ 3 jam & pelatihan dan konstruksi \\
\hline
\end{tabular}

\section{Total Pendampingan 120 jam}

Sumber: Laporan PKM Prodi Teknik Sipil Semester Genap 2017/2018

Adapun hasil pendampingan teknis Cawang berupa gambar teknis pelebaran jembatan penyebrangan jembatan terlihat pada Gambar 3,4,5.

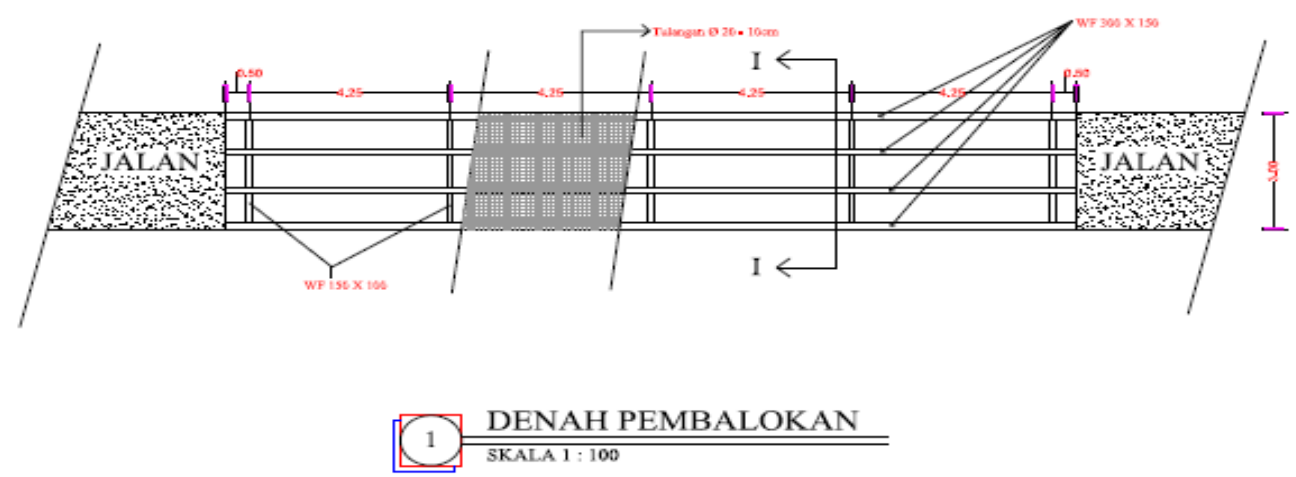

Gambar 6. Denah Pembalokan Pelebaran Jembatan Cawang 
Volume 2, Nomor 1, Tahun 2020 Hal 339 - 351

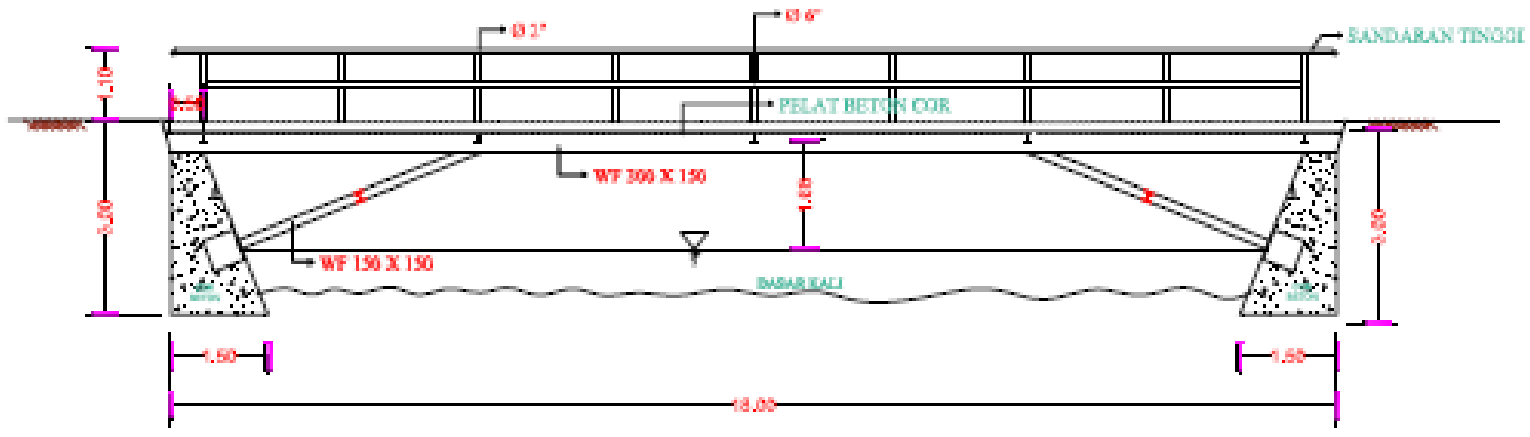

\section{2}

TAMPAK SAMPING

SKALA $1: 100$

Gambar 7. Tampak Samping Pelebaran Jembatan Cawang

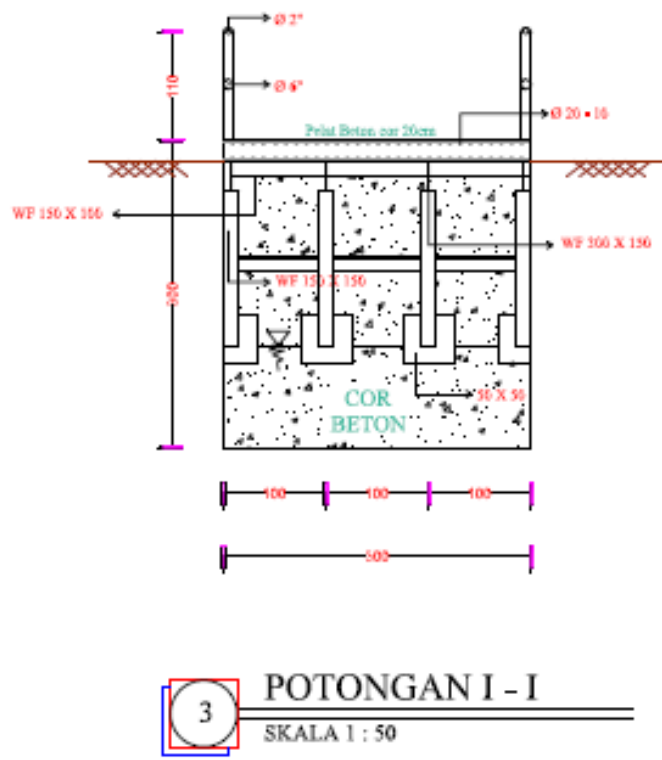

Gambar 8. Potongan I-I StrukturJembatan Cawang

Manfaat dari kegiatan pendampingan yang telah dilakukan adalah sebagai berikut:

a. Secara berkelanjutan masyarakat dapat memahami konsep dan pengertian kondisi lingkungan secara fisik yang aman sehat dan nyaman. b. Secara berkelanjutan masyarakat menyadari pentingnya penataan lingkungan masing masing secara mandiri supaya aman, nyaman dan sehat.

c. Secara berkelanjutan masyarakat memiliki ketrampilan cara memperbaiki jembatan sebagai 
Volume 2, Nomor 1, Tahun 2020 Hal 339 - 351 akses penyeberangan mereka yang kuat dan nyaman secara mandiri

d. Secara berkelanjutan masyarakat makin menyadari bahwa pekerjaan penataan lingkungan mereka secara fisik dapat berhasil jika dilakukan secara mandiri dengan gotong royong.

e. Melalui pendampingan ini Prodi Teknik Teknik Sipil UKI dapat meningkatkan kegiatan dengan melakukan penelitian bersama mahasiswa tentang konstruksi infrastruktur seperti jembatan di lingkungan Kelurahan cawang

f. Prodi Teknik Sipil UKI dapat memberikan pembinaan secara kontinu kepada masyarakat di

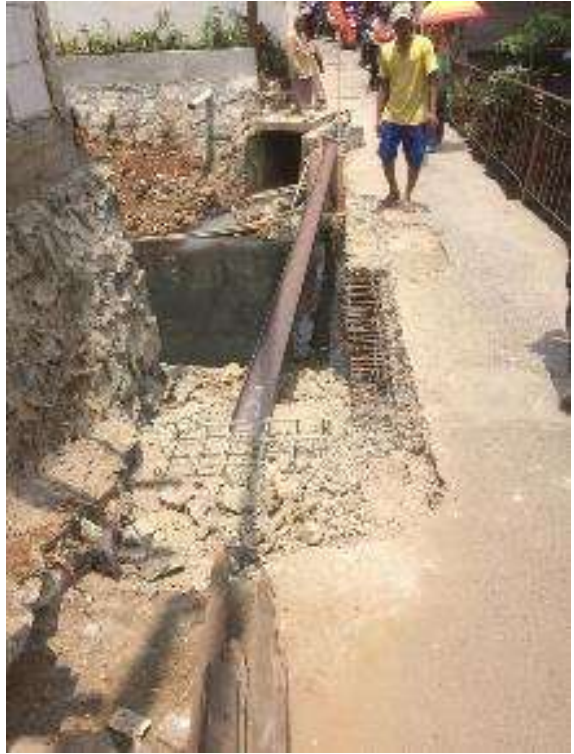

Gambar 9. Pelebaran Jembatan Cawang Swadaya Masyarakat kawasan kelurahan cawang sekaligus menjadi percontohan kawasan yang aman nyaman dan sehat bagi masyarakat di DKI Jakarta

Hasil pendampingan teknis pelebaran jembatan penyebrangan Cawang akan dipublikasikan kepada mahasiswa dan publik melalui seminar ilmiah di Prodi Teknik Sipil UKI serta melalui majalah UKI ataupun Jurnal PKM sehingga penataan lingkungan di kawasan Kelurahan Cawang dapat dipublikasikan kepada masyarakat sekitar.

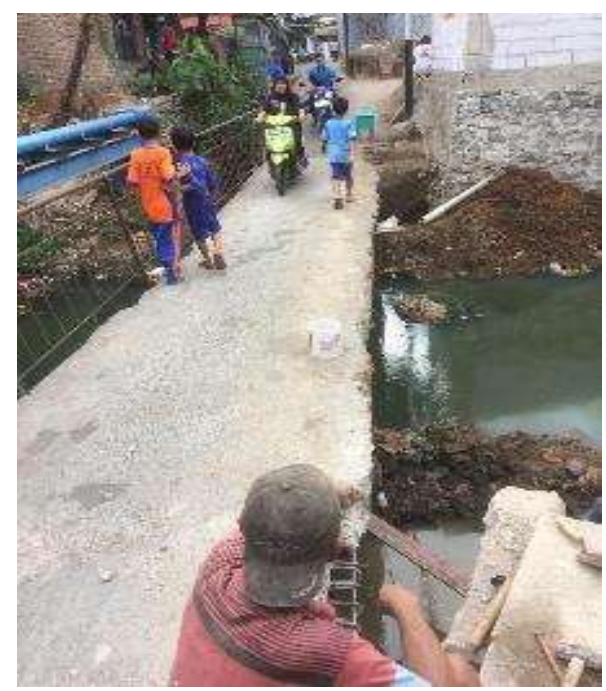

Gambar 10. Persiapan Konstruksi Pelebaran Jembatan Cawang 
Volume 2, Nomor 1, Tahun 2020 Hal 339 - 351

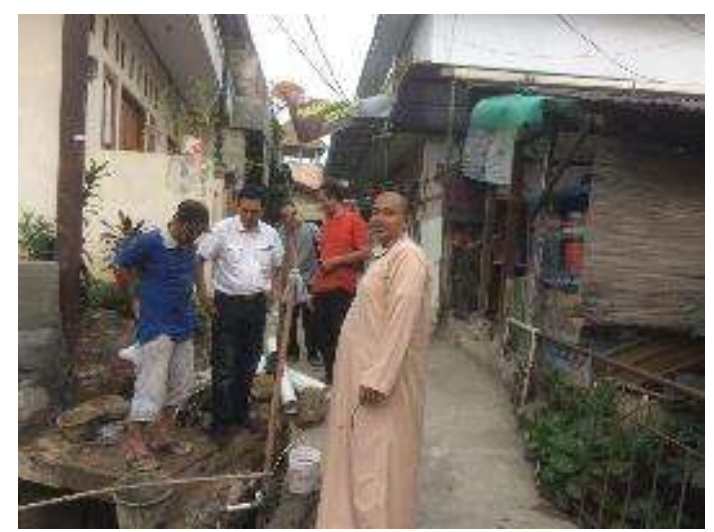

Gambar 11. Pendampingan oleh Tim PKM pada proses konstruksi

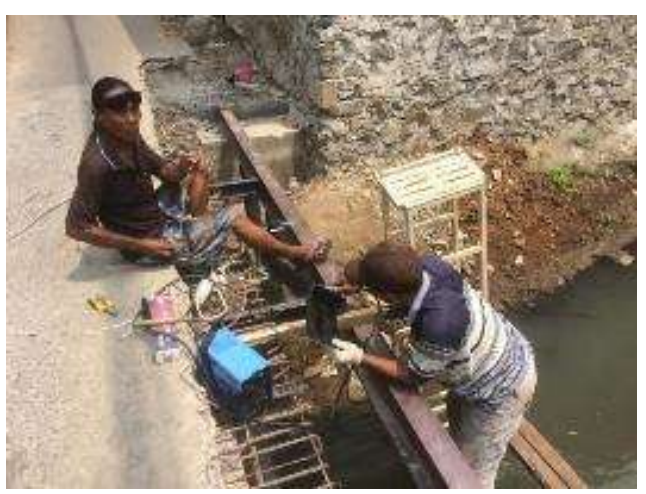

Gambar 12. Pengarahan untuk Pekerjaan Pembesian

\section{KESIMPULAN}

Kegiatan pendampingan teknis pelebaran jembatan penyeberangan sungai kecil di Jl. Haji Nazir Rt 01 Rw 10 Kelurahan Cawang telah meningkatkan pemahaman masyarakat tentang penataan lingkungan di kawasan Kelurahan Cawang. Pendampingan teknis ini dilaksanakan selama total 120 jam yang dimulai dari survei, perencanaan, konsultasi dan asistensi, finalisasi gambar teknis, penyusunan tata kerja, serta persiapan pelaksanaan termasuk

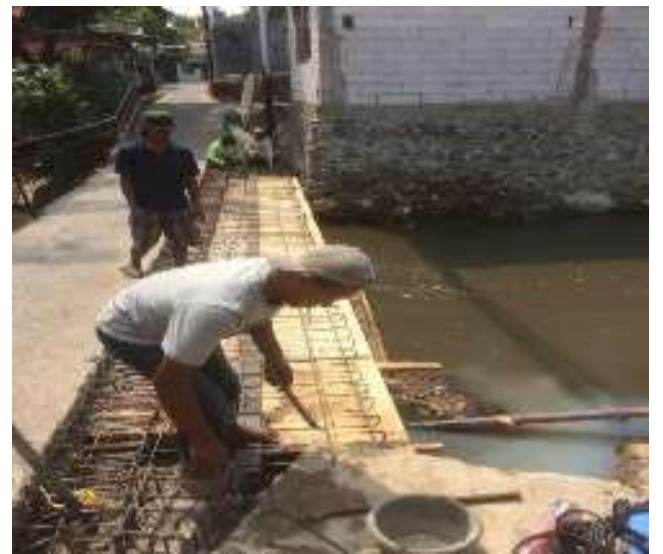

Gambar 13. Pekerjaan pembesian pada Jembatan Cawang

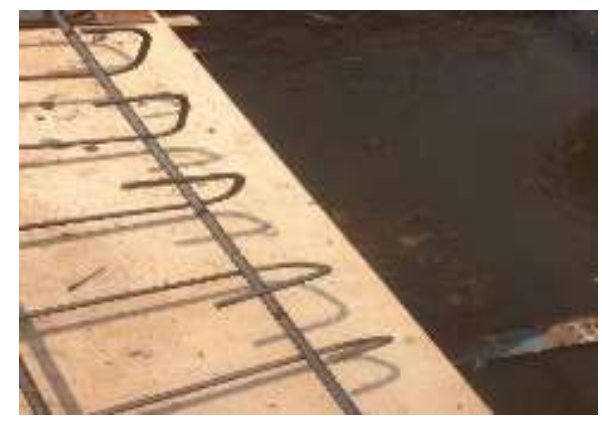

Gambar 14. Detail pembesian pada Jembatan Cawang

pelatihan tenaga kerja saat pelaksanaan. Hasil pendampingan ini telah meningkatkan kesadaran masyarakat dalam memahami konsep dan pengertian kondisi lingkungan secara fisik yang aman, sehat dan nyaman. Proses konstruksi dilaksanakan dengan swadaya masyarakat sehingga terbangun kesadaran masyarakat untuk membangun, memelihara dan mengembangkan kegiatan penataan lingkungan yang berbasiskan kegiatan pada masyarakat itu sendiri. 
Volume 2, Nomor 1, Tahun 2020 Hal 339 - 351

\section{SARAN}

Penataan lingkungan kawasan seperti ini perlu dilaksanakan secara berkelanjutan karena seiring dengan berjalannya waktu kawasan perkotaan akan mengalami keterbatasan ruang kota, permukiman yang padat, sistem sanitasi yang buruk serta minimnya ruang publik masyarakat. Karena itu kawasan kelurahan cawang sekaligus menjadi percontohan kawasan yang

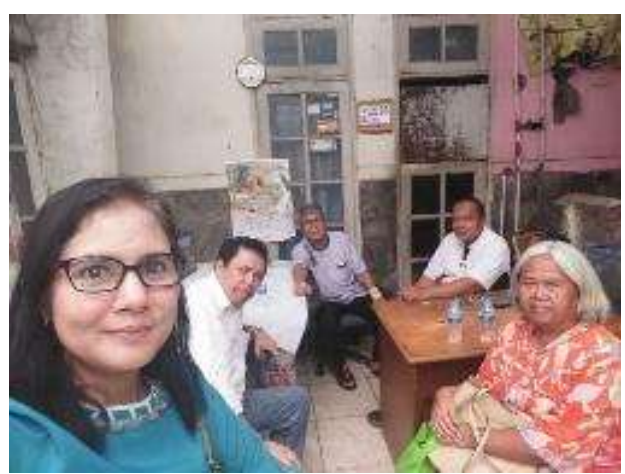

Gambar 5. Tim PKM dengan Lurah Cawang

\section{REFERENSI}

Badan Pusat Statitstik Kota Jakarta Timur (2017). Kecamatan Kramatjati dalam Angka. Jakarta. 210-218.

Dinas Pekerjaan Umum (1992). Bridge Management System (BMS). Jakarta: Dinas Pekerjaan Umum.

Fahimuddin, F., Yelvi, Y., \& Sudardja, H. (2018). Pembangunan Jembatan Penyeberangan Orang RT 03/RW 04 Kampung Pondok Manggis, Kelurahan Bojong Baru, aman nyaman dan sehat bagi masyarakat di DKI Jakarta.

\section{UCAPAN TERIMA KASIH}

Ucapan terimakasih kepada Lurah Cawang yang telah memberikan kesempatan untuk melakukan survei dan asessmen pelebaran jembatan penyebrangan Cawang.

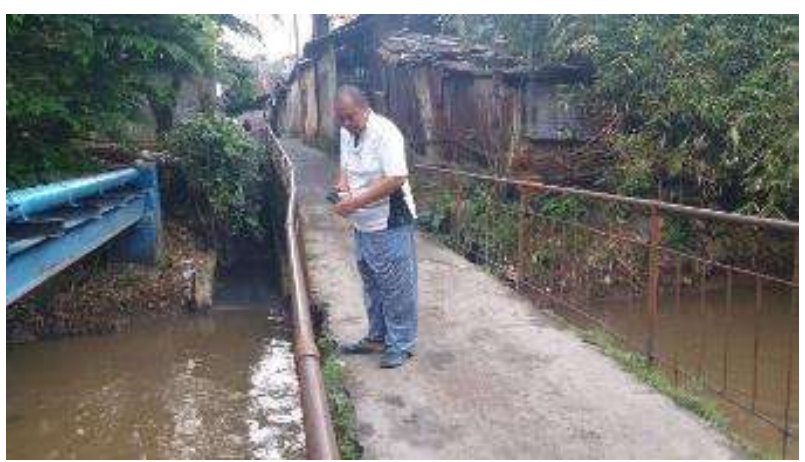

Gambar 6. Lurah Cawang Melakukan Inspeksi Kondisi Eksisting Jembatan Penyebrangan Cawang

$\begin{array}{ll}\text { Kecamatan } & \text { Bojonggede } \\ \text { Kabupaten } & \text { Bogor. Mitra }\end{array}$
Akademia, 1(2).

Kementrian Pekerjaan Umum dan Perumahan Rakyat (2016). Kamus Istilah Pengembangan Wilayah. Laporan PKM Prodi Teknik Sipil FT UKI (2018), Pendampingan Teknis Pada Perbaikan Dan Pelebaran Jembatan Penyeberangan Sungai Kecil Di Jl. Haji Nazir Rt 01 Rw 10 Kelurahan Cawang. LPPM UKI, Jakarta 
Volume 2, Nomor 1, Tahun 2020 Hal 339 - 351

Lim, W.S.W. (1998). Asian New Urbanism, Select Books, Singapore

Makhmud, D. F., Nurhasanah, F., Utami, I. U., Khansha, S., Radnawati, D., \& Syahadat, R. M. (2017). Mewujudkan Kampung Bandan sebagai Kampung Kota Berkelanjutan Menggunakan Pendekatan Asian New Urbanism. Jurnal Arsitektur, Bangunan, \& Lingkungan Vol.6 No.3 Juni 2017 : 91 - 100.

Nugroho, A. C. (2009). Kampung kota sebagai sebuah titik tolak dalam membentuk urbanitas dan Ruang Kota Berkelanjutan. Jurnal Rekayasa, Volume 13 No.3, Desember 2009. 210-218.

Nursyahbani, R., \& Pigawati, B. (2015). Kajian Karakteristik Kawasan

Pemukiman Kumuh di Kampung Kota (Studi Kasus: Kampung Gandekan Semarang). Jurnal Teknik PWK (Perencanaan Wilayah Kota), Vol.4 No.2. 2015. 267-281.

SNI-T-02-2005 (2005) Standar Pembebanan untuk Jembatan, Bandung: Badan Litbang Pemukiman dan Prasarana Wilayah. Jakarta

SNI 03-2833-2008 (2008). Standar Perencanaan Ketahanan Gempa Untuk Jembatan. Badan Standarisasi Nasional. Jakarta Wahyuni, E. (2012) Studi Kelakuan Dinamis Struktur Jembatan Penyeberangan Orang Akibat Beban Individual Manusia Bergerak. Jurnal Teknik Sipil ITS, Vol. 19 No. 3 Desember 2012 